\title{
SETAC Europe Award for Lifetime Achievement in Life Cycle Assessment
}

\author{
Joost Dewaele ${ }^{1}$ \\ Received: 22 March 2018 / Accepted: 30 March 2018 / Published online: 23 May 2018 \\ (C) Springer-Verlag GmbH Germany, part of Springer Nature 2018
}

The SETAC Europe Award for Lifetime Achievement in Life Cycle Assessment is conferred biannually by the SETAC Europe LCA Steering Committee. This award recognizes the outstanding contributions of individuals and/or organizations in promoting life cycle thinking and improving LCA approaches.

This year, the award was presented to Dr. Michael Hauschild. Michael Zwicky Hauschild, born on 26 August 1961, is a professor in Life Cycle Assessment and head of the division for Quantitative Sustainability Assessment at the Department of Management Engineering of the Technical University of Denmark in Kongens Lyngby. Dr. Hauschild is a chemical engineer by formation and holds a Ph.D. in terrestrial ecotoxicity.

$\mathrm{He}$ is widely recognized for his outstanding contributions to life cycle impact assessment. He is especially known for his leading roles in development and documentation of the EDIP midpoint impact assessment method (one of the first full life cycle assessment methods), in advancing consensus on assessment of toxic impacts in LCIA (OMNIITOX/USEtox), and in analyzing social impacts in life cycle assessment. Throughout these activities, Dr. Hauschild is not only praised as a very competent and outstanding scientist, but also as a congenial colleague to collaborate and work with. Dr. Hauschild holds a highly impressive publication record on LCA that spans a very diverse range of contributions with tangible impact that shaped many aspects of LCA as we know it.

On top of the many research activities, Michael Hauschild has served the LCA community greatly by authoring books and book chapters on LCA/LCIA and by teaching on the

Joost Dewaele

dewaele.j@pg.com

1 Procter \& Gamble, Strombeek-Bever, Belgium subjects of environmental sustainability, life cycle assessment, life cycle impact assessment, ecotoxicology, and environmental science to graduate and postgraduate level students and professionals in industry and administration for two decades.

Dr. Michael Hauschild is a former member of the SETAC Europe LCA steering committee, has since 1998 chaired several SETAC Europe and UNEP/SETAC Life Cycle Initiative task forces in the context of toxic impacts in LCA, and is founding chair of the Nordic life cycle association, NorLCA, aimed at dissemination of life cycle thinking in Nordic countries. He has also been active in the International Academy for Production Engineering (CIRP) in agenda setting and support of Life Cycle Engineering activities.

He has been a member of the Editorial Board of The International Journal of Life Cycle Assessment since 1998, subject editor for LCIA of human and ecotoxic impacts since 2008, and he has been subject editor on LCA for the Journal of Industrial Ecology since 2010. $\mathrm{He}$ participated in the development of the European Commission's International Life Cycle Data System (ILCD)'s guideline for LCA and the development of recommendations for life cycle impact assessment under the ILCD system, which is also used in the Commission's respective guidelines for Environmental Footprint of Products and for Organizations (PEF/OEF).

Throughout his career, Dr. Hauschild's dedicated efforts to promote knowledge and research into methods for sustainability assessment thus facilitates more sustainable production and consumption across industrial sectors and society.

Dr. Hauschild received the award during the SETAC Europe Annual meeting, 13-17 May 2018, Rome (Italy). The SETAC Europe Award for Life Time Achievement in Life Cycle Assessment is sponsored by Edana - the international association serving the nonwovens and related industries, www.edana.org. 